\title{
WHAT CAN PHILOSOPHERS LEARN FROM PSYCHOPATHY?
}

\author{
Heidi Maibom \\ University of Cincinnati \\ Original scientific article - Received: 17/05/2018 Accepted: 18/07/2018
}

\begin{abstract}
Many spectacular claims about psychopaths are circulated. This contribution aims at providing the reader with the more complex reality of the phenomenon (or phenomena), and to point to issues of particular interest to philosophers working in moral psychology and moral theory. I first discuss the current evidence regarding psychopaths' deficient empathy and decision-making skills. I then explore what difference it makes to our thinking whether we regard their deficit dimensionally (as involving abilities that are on or off) and whether we focus on primary or secondary psychopathy. My conclusion is that most grand claims about psychopathy settling long-standing debates in moral philosophy and psychology are overblown, but there is much to be learnt from this disorder when it comes to formulating modern theories of moral psychology.
\end{abstract}

Keywords: psychopathy, empathy, decision-making, dimensional approach, rationalism, sentimentalism, responsibility

\section{Introduction}

Psychopathy has been a topic of intense fascination for people in general and philosophers in particular. More or less extraordinary claims about the disorder are circulated. Psychopaths have no conscience, no empathy, are coldblooded killers, and so on. Philosophers have been fascinated by the idea that psychopaths are a class of beings, hitherto thought to be mythical, who are moral knaves. That is, they have no sense of morality whatsoever. What better population to study, then, if one wants to explore moral psychology? As I am about to show, the truth about psychopathy is much more complex than some of the literature would suggest. Any straightforward interpretation of psychopathy as supporting sentimentalism or rationalism in ethics is too simplistic, and the question of their moral and legal responsibility is vexed. My point is not that we cannot use evidence from this disorder in our moral theorizing. To the contrary, I think we can learn a lot from this literature, but it is not what we thought we would.

In this paper, the goal is to introduce the reader to a complex literature that problematizes quick conclusions about what psychopathy, as a disorder, shows about empathy, decision-making, and their respective roles in moral judgment and responsibility. The aim is to raise questions and problems, so as to make the reader rethink the common wisdom about psychopathy and to think more creatively and flexibly about concepts and categories in moral theory and moral psychology. My main aim here is therefore not to propound a certain view on these matters. I've done so elsewhere (Maibom 2005, 2008, 2014, forthcoming). I will, of course, make suggestions and comments, and I cannot guarantee that my presentation will not be partial to my 
own philosophical worldview. Nonetheless, I attempt to be as factual as I can. In what follows, I consider the following four issues: empathy, decision-making, abilities versus interests, and whether psychopathy is a unified kind. I then argue that these four areas are fertile ones for philosophers to engage closer with.

\section{Hard truths about empathy measures}

Lack of empathy is one of the diagnostic features of psychopathy, along with 19 others in the Hare Psychopathy-Checklist Revised (PCL-R, Hare 2003). Consequently, one ought to be on safe ground maintaining that psychopaths lack empathy. There are two problems with this assumption. First, 'empathy' as tested for on the PCL-R is a rather broad category, extending beyond many common philosophical and psychological conceptions of the concept. Second, since psychopathy is diagnosed once a person scores 30 out of 40 points on the $P C L-R$, there is always the possibility that the person scores ' 0 ' on lack of empathy, i.e. shows intact empathy, while scoring high on other features. Nothing excludes the possibility of a psychopath who experiences empathy. How frequently this happens, if at all, is an interesting, but unexplored question (to my knowledge).

For obvious reasons, philosophers have found the idea that an empathy deficit lies at the core of the immorality or amorality of psychopaths enticing. As explanations go, what could be more compelling than that a person cheats, mistreats, and harms others because he lacks empathy for them? Shaun Nichols (2004), for instance, argued that psychopaths are amoral because they lack the motivation, coming from the capacity to empathize with others, to act on moral norms. His idea was that normal human morality melds motivation coming from empathy (or empathy-like emotions) with knowledge of a set of moral norms or rules. His idea was partly inspired by Robert Blair (1995) who had argued that psychopaths lack a so-called 'Violence Inhibition Mechanism,' which is also linked to lack of empathy. This was seen as forming the core of the immoral profile of the psychopath. Blair has later changed his view on the basis of pretty incontrovertible evidence that decision-making capacities are also heavily impacted in psychopathy. Nonetheless, he still maintains that reduced affective responding to the pain and suffering of others lies at the core of the disorder. More recently, David Shoemaker $(2015,2017)$ has argued that whereas psychopaths are appropriate targets for certain responsibility judgments (attributability, for instance), they are not accountable for their actions due to their deficient empathy (see also Ramirez in this issue). In other words, it is perfectly appropriate for us to experience disdain for their rotten characters, but they are not appropriate targets of anger.

And so what has been discussed for a long time among philosophers is not whether psychopaths lack empathy, and what that really amounts to, but rather whether their immorality should be linked to this deficit specifically (Kennett 2002; Maibom 2005, 2014; McGeer 2008). If we set aside their actions, which express a noteworthy lack of empathy for their victims, the actual experimental evidence for lack of empathy in psychopaths is surprisingly mixed. Self-report measures generally support the idea that psychopaths experience intact empathy. I know of at least four studies that show intact performance on the empathic concern subscale of the Interpersonal Reactivity Index (IRI, Davis 1983) (van Borries et al. 2012; Domes et al. 2013; Lishner et al. 2012; Shamay-Tsoory et al. 2010), and only one that shows deficient performance, but only in secondary psychopaths (Mullins-Nelson 2006). Because psychopathy is so closely associated with mendacity and conning, these results tend to be dismissed. It is argued that psychopaths pretend to be normal. And it is certainly quite reasonable to take what they say with a grain of salt. Psychopaths do evince a disconnect between their actions, 
their physiological and neurophysiological reactions, and their verbal reports (see, e.g. Ellis et al. 2016). However, an alternative to their lying about being empathic is that they simply do not understand that they are unempathetic. They may not "get" what empathy is. This would fit with their generally quite poor self-knowledge (Cleckley 1982).

To avoid the confound of psychopaths dissimulating, some studies have used other tools to measure empathy that are thought to be less under conscious control. In general, such studies show stronger support of the idea that psychopaths lack empathy. Their skin conductance and fear potentiated startle responses to observing others in distress are reduced on many tests (Birbaumer 2005; Blair 1999; Herpertz et al. 2001; House and Milligan 1976), and few, if any, show intact performance (but see Gao et al. 2012). Physiological measures, however, are notoriously imprecise. Skin conductance measures arousal. When there is a large increase in it, it shows the person is stressed or experiences fear, or something along those lines. Fear potentiated startle also measures stress or fear. And so the more solid tests of psychopathic lack of empathy actually measure whether pictures of people in distress make psychopaths stressed or fearful. Physiological tests, then, do not measure what psychologists call 'empathic concern' or what philosophers call 'sympathy'. After all, empathic concern is characterized as a soft, caring, and warm emotion, not a stress response (see Batson 1991). Nonetheless, these tests do indicate that psychopaths have a deficient personal distress response to suffering. This type of response is generally not thought to be relevant to moral responding to others because it appears to be primarily self-directed.

Unsurprisingly, the search for empathy, or lack thereof, has moved into the area of neuroscience. And here we have a bunch of studies that show that some empathy related areas - the anterior insula (AI), the anterior cingulate cortex (ACC), the inferior frontal gyrus (IFG), and the amygdala-are underactivated in psychopaths when they are exposed to pictures of people in pain or in painful situations (Birbaumer 2005; Decety et al. 2013a, 2013b; Meffert et al. 2013). However, not all studies show underactivation in such areas (Decety at al. 2014, intact activation in AI). More interestingly, it turns out that certain instructions normalize, or almost normalize, activation in these empathy related areas. In one study, Harma Meffert and colleagues found that if you instruct psychopaths to feel with a hand that is being slapped, their AI, ACC, and IFG show normal activation (suggesting intact empathy). Jean Decety and his collaborators (2015) also found intact activation in the AI (and vmPFC) when they instructed psychopaths to feel with either victims or perpetrators of violence. In another interesting twist, Decety found that when you show psychopaths a picture of a person in a painful situation and instruct them to imagine that this is happening to them, their empathy related areas respond normally or close to normally (Decety et al. 2013a). This contrasts with the level of activation when the instruction is to imagine that this is happening to someone else (abnormally low activation compared to controls).

What should we make of these studies? The most cautious interpretation is, I believe, that psychopaths do not, in the general run of things, empathize much with others. They will report that they do, but since their self-reports do not correspond well with their behavior or their bodily responses, there are reasons to be somewhat skeptical about that claim. It seems plausible, however, that they have the capacity to empathize. Not only do they empathize with people when so instructed (assuming that intact activation of the empathy related areas show empathizing), but also when they imagine that something hurtful or painful is happening to them (depicted to them by a photograph of someone else undergoing that experience). This latter case seems to me to be a bona 
fide example of someone empathizing with a future self. And so the neuroscientific data suggests another complication to the neat picture of psychopathic lack of empathy.

EEG studies are another source of information about what, exactly, is going on in psychopaths when they are exposed to the suffering of others. Here the evidence is somewhat mixed. However, Decety, Lewis, and Cowell (2015) found that the initial orienting response to pain or suffering in others was intact in psychopaths. The later response-the so-called late positive potential (LPP) - was most abnormal. LPP indicates a continued allocation of attentional resources and continued processing of information about the target event. In other words, it reveals a continued preoccupation with what is happening to the suffering other. The substantially weaker response in psychopaths suggests a lack of continued interest in this particular stimulus. So it seems that it is not that psychopaths fail to notice suffering in others, it is merely that it is of limited interest to them. What is even more interesting, particularly to philosophers concerned with moral responsibility, is that these later empathy responses appear to be under conscious control (Decety, Yang, and Chen 2010). Social psychological research also supports the fact that empathy responses are controllable to some extent. For instance, empathic accuracy can be increased by monetary rewards (Hess, Blaison, and Dandeneau 2017; Klein and Hodges 2001). Moreover, emotional mimicry is also affected by such rewards. In effect, a subject can increase or decrease her overall affective empathy when properly motivated (Hess, Blaison, and Dandeneau 2017). This suggests that mimicry of facial expressions is not automatic. Indeed, Ursula Hess and Agneta Fischer (2014) argue that we only mimic facial expressions in affiliative contexts. This, again, suggests that the psychopath's abnormal response to people in distress is merely a heightened version of a relatively pedestrian human tendency; one that is under a good degree of conscious control.

What, then, can philosophers learn about empathy from psychopathy? First, what psychologists measure when they measure 'empathy' is only loosely related to what philosophers typically have in mind by 'empathy.' Most of the studies on psychopaths and empathy measure a distress response to others' suffering, which is well conceptualized as involving primarily stress, fear, or anxiety. Other studies suggest that the deficient response in psychopaths has to do with orienting normally to a threat. We may suppose that other people being in pain constitutes an indirect threat to us, which is why we react to it so strongly. Psychopaths experience a depressed response in these circumstances. This response, however, has little to do with the warm, generous, compassionate response associated with 'empathic concern'. We are not even sure whether the response measured is empathic distress, since measuring otherorientedness directly is problematic. What psychopaths are deficient in may simply be what psychologists call 'personal distress'. Second, psychopaths don't seem to lack empathy altogether. All we have evidence for is reduced responsivity, i.e. an impairment not a lack. This re-conceptualization could be important for assessment of responsibility and planning of treatment. Third, there is the intriguing possibility that psychopaths can empathize perfectly well with others, but they often choose not to. This should not come as a shock, since this is what nice people do all the time when they are overwhelmed by the suffering they are exposed to in real life or on television. Psychopaths may merely have a heightened version of this relatively normal human response. Fourth, if empathy is going to form the basis of psychopaths' deficient moral outlook, then we better make sure that lack of empathy as it is measured in psychopaths is something we believe is morally relevant. If the main component here is to see suffering in others as a threat, some moral philosophers may want to get off the boat. Or, at the very least, they may want to revise their theory of what types of emotional responses are morally relevant. 


\section{Making good decisions}

A number of philosophers have pointed out that psychopaths also have substantial deficits in action planning, execution, and practical reasoning more generally (e.g. Kennett 2002; Maibom 2005). Many of these difficulties are attributable to narrowed attention or, as some researchers say, an attention bottleneck (Baskin-Sommers, Curtin, and Newman 2011). Others may be fear specific, although some researchers ascribe the fear deficit to the attention issues (ibid.).

The anecdotal evidence for decision-making deficits is pretty strong. Robert Hare recounts the story of a psychopath who, having forgotten his wallet, bludgeoned a shopkeeper so as not to have to pay for the beer that he was bringing to a party (Hare 1993, 58-59). Ted Bundy decided to represent himself in court because he distrusted his lawyer, and made his own situation even worse by doing so. One can find anecdote after anecdote in the two foundational books on psychopathy, Robert Hare's Without a Conscience (Hare 1993) and Hervey Cleckley's The Mask of Sanity (Cleckley 1982). The main difference between the two is that Hare's stories describe more violence since he was working in the prison system. Cleckley was a psychiatrist in private practice. Nonetheless, the stories he tells are quite colorful and would have landed his psychopaths in considerable trouble had their family not covered for them. Anecdotes, however, will only take you so far.

The evidence shows that psychopaths have subtle, but nonetheless pervasive, attention deficits. They are relatively insensitive to contextual information that is not the focus of their attention (see, e.g. Hiatt and Newman 2006; Newman and Kosson 1985; Newman et al. 1990). By contrast, non-psychopaths typically attend to many features of actions or situations. Narrowed attention is obviously a problem when peripheral (non-central) information is relevant to interpreting one's situation or the action one is considering performing. The problem is exacerbated by psychopaths also having difficulties shifting attention from one feature of a situation to another (Hiatt and Newman 2006; Newman, Patterson, and Kosson 1987).

Another intriguing feature of psychopaths is that they are relatively insensitive to punishment. It is not that psychopaths do not feel pain, fear, or disappointment (Hoppenbrouwers, Bulten, and Brazil 2016). But complexity and goal pursuit seems to interfere with their responses in a way that differs markedly from ordinary people. Punishment in the context of pursuit of a goal is not processed normally, and does not lead to normal avoidance behavior, whereas straightforward negative reinforcement responses are intact (Hiatt and Newman 2006). However, when simple rewardpunishments contingencies are learned, psychopaths find it much harder to unlearn them than do nonpsychopaths (Blair et al. 2001; Brazil et al. 2013; Newman and Kosson 1986; Newman, Patterson, and Kosson 1987; Newman et al. 1990).

This abnormal reaction to punishment appears to be a function of reduced sensitivity to threat or, if you like, relative fearlessness. As we saw in the previous section, psychopaths do not react defensively to the pain or suffering of others. At least one study also shows that whereas negative social imagery, such as angry faces, leads to retreat in ordinary people, it does not inhibit approach in psychopaths (van Borries et al. 2012). Combined, these two deficits strongly indicate that psychopaths are relatively insensitive to social threats. This contrasts generally with their fear responses to direct threats to themselves, which are intact. For instance, when faced with images of open shark jaws, attacking snakes, or pointed guns, psychopaths have normal physiological reactions, although they are sometimes somewhat unresponsive to unpleasant imagery (Levenston et al. 2000). This could be a function of their attention being strained, as 
indicated by Newman and colleagues (2010) or of how familiar the imagery is, as shown by Baskin-Sommers, Curtin, and Newman (2013). In a range of situations, however, their fear response is intact.

Philosophers have debated whether or not deficient fear responses should count as an emotion specific deficit or a decision-making issue. This discussion is usually about whether sentimentalism or rationalism is supported by psychopaths' deficits. The trouble is that neither sentimentalism nor rationalism have been developed as theories in ways that are particularly sensitive to what we now know about emotion, cognition, and decision-making. One can make a case that intact fear responses are central to good decision-making, and that fear is not the kind of emotion that sentimentalists want to found moral judgments on (Maibom 2005). I expect a nimble sentimentalist can make the opposite claim also. After all, fear is very much an emotion. We should acknowledge that we are in need of new theories of the involvement of reason and emotion in moral judgment that are more sensitive to recent psychological and neurophysiological developments (see, e.g. Kurth 2018).

Deficient decision-making can affect moral reasoning in pretty straightforward ways. I have argued that if one gets transfixed by one's goal and has difficulties keeping a range of other considerations in mind, what might be sacrificed in this battle over attentional resources is information about the welfare of the subject, moral and legal norms, or the categorical imperative, if you like (Maibom 2005). Others argue for more broad sweeping interpretations of psychopaths' practical reasoning impairments. For instance, Jeanette Kennett (2002) maintains that psychopaths do not understand either what ends are or the reasons they generate. Because psychopaths do not suffer from a general impairment of decision-making, we might want to be hesitant about making such sweeping claims (see also Glenn et al. 2017). Nonetheless, one of the things the psychopathy literature indicates is that a number of small and circumscribed deficits can have rather large effects. (For a view that psychopaths do not suffer from impaired practical reason, see Jurjako and Malatesti 2016).

Not paying proper attention to all the ins and outs of a situation is not, of course, a sexy moral deficit. And it does not have the majesty of the failure to grasp a categorical imperative. It is nevertheless pretty obvious that attention and fear impairments play an important role in some of the immoral activities that psychopaths engage in. After all, psychopaths are known to act impulsively or with poor forethought. Whether this issue can be conceptualized in such a way as to give a satisfactory grounding in moral psychological theory is a separate question, but it is one we are not currently in a position to dismiss.

\section{Abilities: the psychopathology of everyday life}

The best way to use psychopathy to show something interesting about human moral psychology is to show that they lack such and such capacities, and show how the correlation with their amorality is more than a simple accident. As should be clear from what I have said so far, there are precious few capacities that psychopaths lack altogether. They do not lack the ability to empathize, they do not lack the capacity to make decent decisions, they are not fearless, and so on. This means that the best way to proceed is to think in terms of deficits, not lacks.

Does shifting the discourse from lacking abilities to deficient ones make any difference? It does. It helps us see this disorder as something that is continuous with nonpathological expressions of similar traits. That this way of thinking about 
psychopathology is becoming more popular is evidenced in the fact that more and more studies of psychopathic traits are conducted online, or in university settings with participants that would never meet the clinical criteria for psychopathy (e.g. Glenn, Raine, and Schug 2009; Lishner at el. 2012). Such studies are nevertheless taken to be informative about psychopathy as a clinical category. What this strategy reveals is that psychopathy is seen to be constituted by a collection of features that can be found in the general population, though typically in less severe forms. In other words, mental illness is seen as continuous with ordinary mental functioning, so that studying the latter can be revelatory about the former. For instance, Glenn, Raine, and Schug (2009) report that high psychopathy scores (in a community sample) are correlated with reduced amygdala activity in emotional moral judgments. This stands to reason, of course. If being mentally ill is merely a matter of the degree and severity of your psychological abnormalities compared to others, then we can study the less severe cases to throw light on the more severe ones. Let me just note in passing that the debate over whether we should regard mental disorder in a categorical or a dimensional fashion is not limited to psychopathy. It is discussed in the Diagnostic and Statistical Manual of Mental Disorders-5, and alternative dimensional schemes are explored in The National Institute of Mental Health's Research Domain Criteria Program (RDoC). The underlying thought is familiar from Freud's thinking about the psychopathology of everyday life, even if only in basic conception (Freud 1914).

Because it is much easier to think in terms of all or nothing, and because it gives rise to much neater explanations, philosophers have had the tendency to apply categorical thinking to psychopathy. Psychopaths have been said to lack a conception of reason (Kennett 2002), lack empathy (Nichols 2004), or something of that sort. This discourse draws a line in the sand between psychopaths and "us" that the data does not support, and dramatizes the disorder considerably. If psychopathic traits are distributed in the population-including the highly educated part of the population-we cannot theorize in ways that make psychopaths abnormal and everybody else normal. And whereas this caution seems straightforward, obvious, but perhaps even unnecessary, it is rarely heeded. Once we take it to heart, however, it subtly changes the way we think about psychopaths and actual human moral agency.

Let me give you one example. It is said that psychopaths lack empathy. As we saw, many measures of empathy detect little to no deficit. Other measures reveal depressed functioning. Moreover, there are significant differences between individual psychopaths here, just as in the general population. But reduced functioning in empathy related tasks is often interpreted as lack of a capacity. This has rather large effects on how we conceptualize what psychopathy is, the degree of responsibility we can ascribe to people suffering from this disorder, and reasonable treatment options. But suppose we think of psychopaths' empathy deficit not so much in terms of other psychiatric populations-such as Borderline Personality Disorder or Autism Spectrum Disorderbut more in terms of ordinary people's everyday failure to empathize. Might that help us understand psychopathic (im)morality better? Let's see. People are very good at empathizing with people they are familiar with and with whom they identify; they have a harder time with strangers, people in different countries, and so on. This fact is part of some people's crusade against empathy being central to morality (Bloom 2016; Prinz 2011). If we look at deficient empathy in psychopaths on the model of deficient empathy in ordinary people, what do we find?

Ordinary people have empathy blind spots for people and creatures that it is in their interest to exploit. Human history is full of such examples: foreigners, "natives", slaves, and women have historically been treated with extreme cruelty and disregard for their wellbeing by people who were quite happy to empathize with "their own". We turn a 
blind eye to the suffering that may be involved in our satisfying our desires or needs. One need only point to the horrific practice of factory farming, which produces most of the meat in the United States. People who consume factory farmed meat are not generally incapable of empathy, nor do they lack feeling when it comes to the plight of nonhuman animals. Many have dogs and other pets they care for greatly. But the group of animals that we have an interest in subjugating, shall we say, is left outside this circle of concern. Why not assume that the lack of empathy we observe in psychopaths is better understood on this model, than positing a rather mysterious and overwhelming lack of care for suffering others? Notice how this interpretation of psychopaths' empathy deficit as motivated fits the data that I presented in section 2.

The idea that deficient empathy is often a matter of having "blind spots" receives additional support from the literature on rape. It is probably not the case that rapists experience a general lack of empathy (Varker et al. 2008). Indeed, there is intriguing evidence that suggests that rapists lack empathy for their particular victim group (Beach and Browne 1999; Fernandez et al. 1999; Fernandez and Marshall 2003, and Fischer). Child molesters can, for instance, be quite empathetic towards adult female rape victims. Their lacuna seems to be specific to children of whatever sex they are interested in. And so merely giving these individuals general empathy training would presumably be useless. Indeed, previous attempts indicate that psychopaths do not improve with such training (Hare 1991). The barrier against empathizing with one's preferred victim group must somehow be removed. So perhaps new models of treatment that address motivational issues in empathy, specifically, should be explored. And if such issues are common in ordinary people, we have lots of data to work with to design new treatments.

If we move on to consider how an approach to psychopathy in terms of deficient, not lacking, abilities affect ascriptions of responsibility, we find that it leaves no quick way of absolving psychopaths for their harmful actions. If psychopaths do not simply lack empathy, we cannot absolve them for their harmful actions by reference to this fact preventing them from truly understanding harm norms. Instead, we must show that the empathy impairment they suffer from is sufficient to render their moral understanding so deficient that they cannot truly be said to know right from wrong. Alternatively, we must show that the empathy deficit is of a kind that attenuates responsibility. It must, in other words, be morally relevant. Determining whether this is the case is going to be more difficult than if we were simply dealing with an absent ability (for a more detailed discussion, see Jefferson and Sifferd in this issue).

\section{Primary versus secondary psychopathy}

In the philosophical literature psychopathy is often presented as if it were a unified category. And in a way it is, of course. It is a category generally accepted by researchers and professionals-although it does not appear in the DSM anymore (it is largely subsumed under Antisocial Personality Disorder) - and it is predictive of things like recidivism (Hare 2003). It is therefore tempting to think it is a psychiatric kind, i.e. a psychiatric equivalent of a natural kind (Malatesti and McMillan 2014). But psychopathy, as it is currently diagnosed, is unlikely to constitute $a$ kind (e.g. Brzović, Jurjako, and Šustar 2017). For one, there is now general agreement that psychopathy comes in two types: primary and secondary, or low-anxious and high-anxious (e.g. Hicks et al. 2004; Kosson et al. 2016). This division is significant because the behavior of particular interest to researchers-immoral and criminal behavior-appears to spring from at least partially different causes in the two groups. If the two subtypes are 
distinct, this might also explain why the data on psychopaths' moral abilities is so mixed (for a review, see Maibom forthcoming). Let us have a quick look at this issue.

James Blair (1995) first argued that psychopaths have a deficient Violence Inhibition Mechanism. This deficit gives rise to a range of other deficits: in empathy, in guilt and remorse, and so on. Blair later became interested in different forms of aggression, namely instrumental and reactive aggression (Blair, Mitchell, and Blair 2005). He then argued that what sets psychopaths apart from other criminals is the high degree of instrumental aggression they engage in. As the term indicates, reactive aggression is aggression following an event, such as an insult, an attack, or something similar. It is a retaliatory response. High degrees of reactive aggression are associated with impulsivity. By contrast, instrumental aggression is aggression not directly provoked by a preceding event, but used to get some resource of interest to the perpetrator. It is usually premeditated. An example would be to hurt someone and threaten to hurt them more, if they do not comply with certain demands. Blair builds his theory around this particular type of aggression, arguing that amygdala dysfunction lies at the core of psychopathy, with its distinctive patterns of instrumental aggression. The basic idea is that a level of affective insensitivity on the part of psychopaths facilitates such behavior. On his view, high levels of reactive aggression are more common in children diagnosed with Conduct Disorder and adults with Antisocial Personality Disorder (Blair, Mitchell, and Blair 2005). He tends to think of these groups not in terms of psychopathy.

Blair's point is not, of course, that psychopaths only engage in instrumental violence, but that the high frequency with which they do sets them apart from other criminals. As a matter of fact, psychopathy is predictive of aggression in inpatient settings, whether reactive or instrumental (Stafford and Cornell 2003). Since secondary or high-anxious psychopaths are known for their reactive aggression (Kosson et al. 2016; Swogger et al. 2010), Blair's account is less suited to explain psychopathy per se than primary psychopathy specifically. After all, the explanation for high levels of reactive aggression is notably different from that provided by Blair for the high levels of instrumental aggression. In a later paper, Blair argues that impairments in stimulus-reinforcement learning and response reversal gives rise to frustration, which makes psychopaths more susceptible to reactive aggression also. The impairment is not due to deficient amygdala functioning, but to dysfunction in the ventromedial prefrontal cortex (Blair 2010). If it is indeed true that the two forms of aggression line up reasonably well with the primary vs. secondary distinction, the two groups cannot be understood, treated, or assigned responsibility on the same model.

Now, one of the aspects of psychopathy that has received the most focus is their relative lack of concern for others, primarily in the context of violence. Increased violence has, in turn, been associated with deficient empathy. But there is evidence that secondary psychopaths are more violent than primary psychopaths (Hicks et al. 2004; Kimonis et al. 2012; Vidal, Skeem, and Camp 2010), and their violence tends to be reactive. What is interesting about this fact is that secondary psychopaths are primarily characterized by behavioral and lifestyle issues, including impulsivity, but not affective deficits. They may not score high on lack of empathy, for instance. Kimonis et al. (2012) found that secondary, but not primary, psychopaths accord substantial attentional resources to processing emotional faces. Moreover, higher levels of anxiety are associated with better performance on startle probes, a typical measure of emotional responsivity to unpleasant imagery, such as harm to others (Justus and Finn 2006). Female psychopaths have also been found to have more intact responses to unpleasant and 
threatening stimuli than male psychopaths (Justus and Finn 2006), possibly because women are more prone to fear and anxiety than are men (Campbell 2006). ${ }^{1}$

If this distinction between primary and secondary forms of psychopathy holds, we need to rethink some of the common conceptualizations of psychopathy. Secondary psychopathy, on this picture, is more like Antisocial Personality Disorder and may be amenable to treatment as such. Early proponent of the distinction, Benjamin Karpman, argued that secondary psychopaths suffer from an emotional disturbance, not deficient affectivity, and are amenable to psychotherapeutic treatment on the basis of their capacity for moral training (Karpman 1948). Although the surface features of disregard for the rights and wellbeing of others are shared between the two types of psychopaths, the origins of these attitudes are likely to be quite different (see also Brazil et al. 2018). For moral psychologists, this is of enormous significance when it comes to conceptualizing the various pathways to morality and immorality.

The most obvious candidate for the classical psychopath, as far as philosophers are concerned, is the primary psychopath. In psychiatric parlance, such psychopaths are high on $P C L-R$ Factor 1 issues, i.e. emotional and interpersonal deficits. They tend to suffer from deficient emotional reactivity and depressed interpersonal emotions, such as guilt, shame, remorse, and empathy (probably: personal distress). But they are not likely to be the most violent of psychopaths. They may engage more in manipulative, exploitative, and conning behaviors. And when they are violent, it is more likely to be planned and goal-directed (Blair, Mitchell, and Blair 2005; Hart and Dempster 1997). It is this kind of psychopathy, presumably, that is the best target for people who believe that having the right kind of emotional sensitivity to others is necessary for being morally responsive to them. It is important to note, however, that the premeditation that is involved in these types of behaviors usually counts against a person being excused for their immoral actions, particularly if this can be combined with a decent declarative knowledge of right and wrong.

There is a real possibility, then, that most of the work on psychopaths' affective profile and moral capacity is based on research which conflates two interestingly different subtypes. This could explain why the data is often so maddeningly conflicting (Brazil et al. 2018). If there are various pathways to immorality or amorality, we need more new research that examines the distinctive contributions of the different facets of psychopathy to moral judgment and behavior.

\section{Some take-home messages for the curious}

I have picked four themes in psychopathy research that I believe are of particular interest to philosophers. A common theme unites them; psychopathy is a much more complex and multifaceted disorder than it is often given credit for. It may not, in fact, be one disorder at all. And whereas the criminal histories of many psychopathic individuals are long and shocking, their actual documentable deficits are often quite subtle, and very specific. We can make no sweeping statements about psychopaths such as: they lack empathy or they lack practical reason. But here are some things we can learn. First, the specific empathy deficit we have evidence for in psychopaths is an impaired distress

\footnotetext{
${ }^{1}$ Mullins-Nelson et al. (2013) found that primary psychopaths score within the normal range on IRI-EC, whereas secondary psychopaths score abnormally low on IRI-EC, contrary to what one would expect from factor scores. This lends further support to the idea that primary psychopaths are either more deceptive or simply have less understanding of themselves because of their emotional deficit. It also suggests that the lack of empathy measured in secondary psychopaths may be due to hostility towards others, rather than affective insensitivity to them.
} 
response to distress cues. What does this amount to? Compared to ordinary people, psychopaths experience less fear, anxiety, and defensiveness in face of suffering others. There are many reasons to think that this is highly relevant to the ease with which psychopaths violate harm norms. But if this is right, it means that this type of response in ordinary people may underpin their adherence to moral and legal norms too. It is not a response that has been accorded much attention by moral psychologists or philosophers, however. Perhaps it is time for this to change. Second, we have no basis upon which to conclude that psychopaths are incapable of forming a conception of reason based on their rather subtle and specific learning impairments. But we do have reasons to think that fear and anxiety play important roles in learning and good decision-making, and this has ramifications for how to think of moral psychology (see also Kurth 2018). Third, what is emerging is a complex picture of various impairments in abilities that are imperfectly instantiated in the population at large. For instance, people are more or less empathic. Moreover, the empathy impairment psychopaths (primary psychopaths?) suffer from may have more to do with their being relatively uninterested in others' suffering than with their ability to feel distress at others' distress. How to conceptualize such a deficit within theories of responsibility and punishment is an urgent and fascinating problem. Exploring this issue further may help us to think of abilities themselves quite differently. Fourth, disaggregating subtypes of common mental disorders may turn out to be crucial for drawing more wide-ranging conclusions from psychological results with such populations. There is a real possibility that the psychopathy literature is currently of limited help in revealing the true correlations between immoral behavior, moral judgment, and psychological capacities, such as attention, anxiety, empathy, and learning. That ought to make us a bit more careful about positing our own favored causation model-no empathy, hence no true moral understanding, say-to a complex phenomenon such as psychopathy.

It is, of course, somewhat dismaying to have to recognize that a disorder that seemed so perfectly suited for settling disputes in moral psychology is so maddeningly complex. But post-truth age or not, the evidence is pretty solid. It is clear that both affective impairments or disturbances and decision-making and learning deficits contribute to poor compliance with moral and legal norms in psychopaths. What philosophers want to know is whether the psychological underpinnings are morally relevant or not. And that is an important question to be sure. But we cannot use simplistic formulations of sentimentalism and rationalism, such as Hume versus Kant, to help us here. For their view of what reason is differs markedly from what we now know is involved in making good decisions. For instance, intact affective responding to threats clearly is one important learning mechanism without which you will develop relatively poor decisionmaking skills (Damasio 1994). We can decide to say this supports rationalism or sentimentalism, but why not update our philosophy? Why not think of modern and more empirically viable ways of conceptualizing what we have discovered? Instead of fitting psychopathy into a procrustean bed of philosophical dignitaries, perhaps it is time to update our view of moral psychology.

\section{REFERENCES}

Baskin-Sommers, A. R., J. J. Curtin, and J. P. Newman. 2011. Specifying the attentional selection that moderates the fearlessness of psychopathic offenders. Psychological Science 22: 226-234. 
Baskin-Sommers, A. R., J. J. Curtin, and J. P. Newman. 2013. Emotion-modulated startle in psychopathy: Clarifying familiar effects. Journal of Abnormal Psychology 122: 458-468.

Batson, C. D. 1991. The Altruism Question: Toward a Social-Psychological Answer. Hove, UK: Lawrence Erlbaum Ass.

Birbaumer, N., R. Veit, M. Lotze, et al. 2005. Deficient fear conditioning in psychopathy. Archives of General Psychiatry 62: 799-805.

Blair, R. J. R. 1995. A cognitive developmental approach to morality: Investigating the psychopath. Cognition 57: 1-29.

Blair, R. J. R. 1999. Responsiveness to distress cues in the child with psychopathic tendencies. Personality and Individual Differences 27: 135-145.

Blair, R. J. R. 2010. Psychopathy, frustration, and reactive aggression: The role of the ventromedial prefrontal cortex. British Journal of Psychology 101: 383-399.

Blair, R. J. R., E. Colledge, and D. Mitchell. 2001. Somatic markers and response reversal: Is there orbitofrontal cortex dysfunction in boys with psychopathic tendencies? Journal of Abnormal Child Psychology 29: 499-511.

Blair, R. J. R., D. Mitchell, and K. Blair. 2005. The Psychopath: Emotion and the Brain. Oxford: Blackwell.

Bloom, P. 2016. Against Empathy: The Case for Rational Compassion. New York: Ecco.

van Borries, A., I. Volman, E. de Bruijn, B. Bulten, R. Verkes, and K. Roelofs. 2012. Psychopaths lack the automatic avoidance of social threat: Relation to instrumental aggression. Psychiatry Research 200: 761-766.

Brazil, I. A., J. D. M. van Dongen, J. H. R. Maes, R. B. Mars, and A. R. Baskin-Sommers. 2018. Classification and treatment of antisocial individuals: From behavior to biocognition. Neuroscience and Biobehavioral Reveiws, 91, 259-77.

Brazil, I. A., I. Scheper, B. H. Bulten, R. P. C. Kessels, R. J. Verkes, and E. R. A. de Bruijn. 2013. Reversal deficits in psychopathy in explicit but not implicit learning conditions. Journal of Psychiatry \& Neuroscience 38: e13-20.

Brzović, Z., M. Jurjako, and P. Šustar. 2017. The kindness of psychopaths. International Studies in the Philosophy of Science 31: 189-211.

Campbell, A. 2006. Sex differences in direct aggression: What are the psychological mediators? Aggression and Violent Behavior, 11, 237-264.

Cleckley, H. 1982. The Mask of Sanity. St. Louis, MO: Mosby Co.

Damasio, A. 1994. Descartes' Error: Emotion, Reason, and the Human Brain. New York: Penguin Press.

Davis, M. 1983. Measuring individual differences in empathy: Evidence for a multidimensional approach. Journal of Personality and Social Psychology, 44, 113126.

Decety, J., C. Chen, C. Harenski, and K. Kiehl. 2013a. An fMRI study of affective perspective taking in individuals with psychopathy: Imagining another in pain 
does not evoke empathy. Frontiers in Human Neuroscience 7:489. doi: 10.3389/ fnhum.2013.00489

Decety, J., C. Chen, C. Harenski, and K. Kiehl. 2015. Socioemotional processing of morally-laden behavior and their consequences for others in forensic psychopaths. Human Brain Mapping 36: 2015-2026.

Decety, J., K. L. Lewis, and J. M. Cowell. 2015. Specific electrophysiological components disentangle affective sharing and empathic concern in psychopathy. Journal of Neurophysiology 114: 493-504.

Decety, J., C. Chen, C. Harenski, and K. Kiehl. 2013a. An fMRI study of affective perspective taking in individuals with psychopathy: Imagining another in pain does not evoke empathy. Frontiers in Human Neuroscience, 7:489. doi: 10.3389/ fnhum.2013.00489

Decety, J., L. Skelly, and K. Kiehl. 2013b. Brain responses to empathy-eliciting scenarios involving pain in incarcerated individuals with psychopathy. JAMA Psychiatry 70: 638-645.

Decety, J., L. Skelly, K. Yoder, and K. Kiehl. 2014. Neural processing of dynamic emotional facial expressions in psychopaths. Social Neuroscience 9: 36-49.

Decety, J., Y. Yang, and C Chen. 2010. Physicians down-regulate their pain empathy response: An event-related brain potential study. NeuroImage 50: 1676-1682.

Domes, G., P. Hollerbach, K. Vohs, A. Mokros, and E. Habermayer. 2013. Emotional empathy and psychopathy in offenders: An experimental study. Journal of Personality Disorders 27: 67-84.

Ellis, J. D., H. S. Schroder, C. J. Patrick, and J. S. Moser. 2016. Emotional reactivity and regulation in individuals with psychopathic traits: Evidence for a disconnect between neurophysiology and self-report. Psychophysiology 54: 1574-1585.

Fernandez, Y. M., and W. L. Marshall. 2003. Victim empathy, social self-esteem, and psychopathy in rapists. Sexual Abuse: A Journal of Research and Treatment 15: 1126.

Fernandez, Y. M., W. L. Marshall, S. Lightbody, and C. O’Sullivan. 1999. The child molester empathy measure: Description and examination of its reliability and validity. Sexual Abuse: A Journal of Research and Treatment 11: 17-31.

Fischer, D., A. Beech, and K. Browne. 1999. Comparison of sex-offenders to nonoffenders on selected psychological measures. International Journal of Offender Therapy and Comparative Criminology 43: 473-591.

Freud, S. 1914. The Psychopathology of Everyday Life. A.A. Brill (transl.). London: T. Fischer Unwin Ltd.

Gao, Y., A. Raine, and R. A. Schug. 2012. Somatic aphasia: Mismatch of body sensations with autonomic stress reactivity in psychopathy. Biological Psychology 90: 228233.

Glenn, A., A. Raine, and A. Schug. 2009. The neural correlates of moral decision-making in psychopathy. Molecular Psychiatry 14: 5-6. 
Glenn, A., L. M. Efferson, R. Iyer, and J. Graham. 2017. Values, goals, and motivations associated with psychopathy. Journal of Social and Clinical Psychology 36: 108125.

Hare, R. 1993. Without Conscience: The Disturbing World of the Psychopaths Among Us. New York: Simon \& Schuster Inc.

Hare, R. 2003. The Hare Psychopathy Checklist-Revised, 2nd Ed. Toronto: Mental Health Services.

Hart, S. D., and R. Dempster. 1997. Impulsivity and psychopathy. In Impulsivity: Theory, Assessment and Treatment, eds. D. Webster and M. Jackson, 212-232. New York: Guilford Press.

Herpertz, S. C., U. Werth, G. Lukas, et al. 2001. Emotion in criminal offenders with psychopathy and borderline personality disorder. Archives of General Psychiatry 58: 737-745.

Hess, U., C. Blaison, and S. Dandeneau. 2017. The impact of rewards on empathic accuracy and emotional mimicry. Motivation and Emotion 41: 107-112.

Hess, U., and A. Fischer. 2014. Emotional mimicry: When and why we mimic emotions. Social and Personality Psychology Compass 8: 45-57.

Hiatt, K., and J. P. Newman. 2006. Understanding Psychopathy: The Cognitive Side. In Handbook of Psychopathy, ed. C. Patrick, 334-352. New York: The Guildford Press.

Hicks, B., K. Markon, C. Patrick, R. Krueger, and J. P. Newman. 2004. Identifying psychopathy subtypes on the basis of personality structure. Psychological Assessment 16: 276-288.

Hoppenbrouwers, S. S., B. H. Bulten, and I. A. Brazil. 2016. Parsing fear: A reassessment of the evidence for fear deficits in psychopathy. Psychological Bulletin 142: 573600

House, T. H., and W. L. Milligan. 1976. Autonomic responses to modeled distress in prison psychopaths. Journal of Personality and Social Psychology 34: 556-560.

Jurjako, M., and L. Malatesti. 2016. Instrumental rationality in psychopaths: Implications from learning tasks. Philosophical Psychology 29: 717-731.

Justus, A. N., and P. R. Finn. 2006. Startle-modulation in non-incarcerated men and women with psychopathic traits. Personality and Individual Differences 43: 20572071.

Karpman, B. 1948. The myth of the psychopathic personality. American Journal of Psychiatry 104: 523-534.

Kennett, J. 2002. Autism, empathy, and moral agency. Philosophical Quarterly 52: 340357.

Kimonis, E. R., P. J. Frick, E. Cauffman, A. Goldweber, and J. Skeem. 2012. Primary and secondary variants of juvenile psychopathy differ in emotional processing. Developmental Psychopathology 24: 1091-1103. 
Klein, K., and S. Hodges. 2001. Gender differences, motivation, and empathic accuracy: When it pays to understand. Personality and Social Psychology Bulletin 27: 720730 .

Kosson, D. S., M. J. Vitacco, M. T. Swogger, and B. L. Steurwald. 2016. Emotional experiences of the psychopath. In The Clinical and Forensic Assessment of Psychopathy: A Practitioner's Guide, ed. C. B. Gacono, 73-95. Mahwah: NJ: Lawrence Erlbaum Associates.

Kurth, C. 2018. The Anxious Mind: An Investigation into the Varieties \& Virtues of Anxiety. Cambridge, MA: MIT Press.

Levenston, G., C. Patrick, M. Bradley, and P. Lang. 2000. The psychopath as observer: Emotion and attention in picture processing. Journal of Abnormal Psychology 109: 373-385.

Lishner, D., M. Vitacco, P. Hong, J. Mosley, K. Miska, and E. Stocks. 2012. Evaluating the relation between affective psychopathy and empathy: Two preliminary studies. International Journal of Offender Therapy and Comparative Criminology 56: 11611181.

Maibom, H. L. 2005. Moral unreason: The case of psychopathy. Mind \& Language 20: 237-257.

Maibom, H. L. 2008. The mad, the bad, and the psychopath. Neuroethics 1: 167-184.

Maibom, H. L. 2014. Without fellow feeling. In Being Immoral: Psychopaths and Moral Indifference, ed. T. Schramme, 91-114. Cambridge, MA: MIT Press.

Maibom, H. L. Forthcoming. Responsibility in the age of neuroscience. In Oxford Handbook of Moral Psychology, eds. J. Doris and M. Vargas. Oxford: Oxford University Press.

Malatesti, L., and J. McMillan. 2014. Defending psychopathy: An argument from values and moral responsibility. Theoretical Medicine and Bioethics 35: 7-16.

McGeer, V. 2008. Varieties of moral agency: Lessons from autism (and psychopathy). In Moral Psychology, Vol. 3: The Neuroscience of Morality: Emotion, Brain Disorders, and Development, ed. W. Sinnott Armstrong, 227-258. Cambridge, MA: MIT Press.

Meffert, H., V. Gazzola, J. A. den Boer, et al. 2013. Reduced spontaneous but relatively normal deliberate vicarious representations in psychopathy. Brain 136: 25502562 .

Mullins-Nelson, J. L., R. T. Salekin, and A-M. R. Leistico. 2006. Psychopathy, empathy, and perspective taking ability in a community sample: Implications for the successful psychopath concept. Journal of Forensic Mental Health 5: 133-149.

Newman, J., and D. Kosson. 1986. Passive avoidance learning in psychopathic and nonpsychopathic offenders. Journal of Abnormal Psychology 96: 257-263.

Newman, J., C. Patterson, and D. Kosson. 1987. Response perseveration in psychopaths. Journal of Abnormal Psychology 96: 145-148. 
Newman, J., C. Patterson, E. Howland, and S. Nichols. 1990. Passive avoidance in psychopaths: The effects of reward. Personality and Individual Differences 11: 1101-1114.

Newman, J. P., J. J. Curtin, J. D. Bertsch, and A. R. Baskin-Sommers. 2010. Attention moderates the fearlessness of psychopathic offenders. Biological Psychiatry 67: 66-70.

Nichols, S. 2004. Sentimental Rules: On the Natural Foundations of Moral Judgment. New York: Oxford University Press.

Prinz, J. 2011. Is empathy necessary for morality? In Empathy: Philosophical and Psychological Perspectives, eds. A. Coplan and P. Goldie, 211-229. New York: Oxford University Press.

Shamay-Tsoory, S., H. Harari, J. Aharon-Perez, Y. Levkovich. 2010. The role of orbitofrontal cortex in affective theory of mind deficits in criminal offenders with psychopathic tendencies. Cortex 46: 668-677.

Shoemaker, D. 2015. Responsibility from the Margins. Oxford: Oxford University Press.

Shoemaker, D. 2017. Empathy and moral responsibility. In Routledge Handbook of Philosophy of Empathy, ed. H. L. Maibom, 242-252. London and New York: Routledge.

Stafford, E., and D. G. Cornell. 2003. Psychopathy scores predict adolescent inpatient aggression. Assessment 10: 102-112.

Swogger, M. T., Z. Walsh, R. J. Houston, S. Cashman-Brown, and K. R. Conner. 2010. Psychopathy and Axis I psychiatric disorders: Relationship to reactive and proactive aggression. Aggressive Behavior 36: 45-53.

Varker, T., G. J. Devilly, T. Ward, and A. R. Beech. 2008. Empathy and adolescent sexual offenders: A review of the literature. Aggression and Violent Behavior 13: 251-260.

Vidal, S., J. Skeem, and J. Camp. 2010. Emotional intelligence: Painting different paths for low-anxious and high-anxious psychopathic variants. Law and Human Behavior 34: $150-163$ 